\title{
Caring for relatives with chronic obstructive pulmonary disease: how does the disease severity impact on family carers?
}

\section{Caring for relatives with chronic obstructive pulmonary disease}

\section{Daniela Figueiredo, Raquel Gabriel, Cristina Jácome, Joana Cruz and Alda Marques}

Daniela Figueiredo PhD, Degree in Educational Sciences - Corresponding author Senior Lecturer at School of Health Sciences, University of Aveiro (ESSUA), Portugal Research member at Unidade de Investigação e Formação sobre Adultos e Idosos (UniFAI), Portugal daniela.figueiredo@ua.pt

Raquel Gabriel MSc, Degree in Gerontology

Research fellow at School of Health Sciences, University of Aveiro (ESSUA), Aveiro, Portugal PhD student at Department of Health Sciences, University of Aveiro (SACS), Aveiro, Portugal raquelgabriel@ua.pt

Cristina Jácome MSc, PT

Research fellow at School of Health Sciences, University of Aveiro (ESSUA), Aveiro, Portugal cristinajacome@ua.pt

Joana Cruz MSc, PT

PhD student at Department of Health Sciences, University of Aveiro (SACS), Aveiro, Portugal joana.cruz@ua.pt

Alda Marques PhD, MSc, PT

Senior Lecturer at School of Health Sciences, University of Aveiro (ESSUA), Portugal

Research member at Unidade de Investigação e Formação sobre Adultos e Idosos (UniFAl), Portugal amarques@ua.pt

Corresponding author: Daniela Figueiredo, School of Health Sciences, University of Aveiro (ESSUA); Agras do Crasto - Campus Universitário de Santiago, Edifício 30, 3810-193 Aveiro, Portugal; Telephone: 00351234372 462; E-mail address: daniela.figueiredo@ua.pt 


\section{Caring for relatives with chronic obstructive pulmonary disease: how does the disease severity impact on family carers?}

\section{Abstract}

Chronic Obstructive Pulmonary Disease (COPD) is a major cause of disability, morbidity and mortality in old age, representing a significant burden for families. However, information on the impacts of caring for relatives with COPD on carers' psychological health is limited. This study aimed to analyse the subjective burden of family carers of people with early and advanced COPD and its predictor variables.

A cross-sectional study was conducted. A structured questionnaire was used to collect sociodemographics and care-giving characteristics. Self-rated physical and mental health were measured by two items from the International Classification of Functioning, Disability and Health checklist. The Hospital Anxiety and Depression Scale was used to assess anxiety and depression. Subjective burden was assessed with the Carers' Assessment of Difficulties Index (CADI). Descriptive and inferential analyses were performed.

A total of 167 family carers participated: 113 were caring for people with early and 54 with advanced COPD. Both groups presented anxiety/depression symptoms. Those caring for people with advanced COPD reported higher subjective burden, more depression symptoms and poorer self-rated mental health than those caring for early COPD. Advanced COPD (Coefficient 6.7), depression (Coefficient 6.3), anxiety (Coefficient 5.6), care-giving hours per week (Coefficient 3.2) and self-rated mental health (Coefficient 2.8) were significant predictors of carers' subjective burden.

The findings suggest that the gradual course of COPD imposes an increasing physical and emotional burden on carers, with negative impacts on their psychological health. The study highlights the relevance of early interventions in the context of COPD to prevent carers' burden.

Key-Words: family carers; early COPD; advanced COPD; perceived burden; psychological health 


\section{Caring for relatives with chronic obstructive pulmonary disease: how does the disease severity impact on family carers?}

\section{Introduction}

Chronic Obstructive Pulmonary Disease (COPD) is a major cause of morbidity, disability and mortality worldwide (Pauwels \& Rabe, 2004; Simpson \& Rocker, 2008). Its global prevalence is around $10 \%$ in people older than 40 years old (Halbert et al., 2006), being frequently underdiagnosed and undertreated as a consequence of its gradual course and old age of patients (Rodriguez Gonzalez-Moro et al., 2009). However, as the global population ages, the burden of COPD will increase in coming years (Mannino \& Braman, 2007). People living with COPD progressively experience a range of troublesome symptoms (e.g., breathlessness, fatigue, lack of mobility, sleep disturbance, sputum production, uncontrolled coughing and pain), which inevitably affects their quality of life (Barnett, 2005; Gardiner et al., 2010). Moreover, they are often restricted in their everyday life, not just due to the physical constraints caused by the disease, but also because of the fear associated with the worsening of symptoms, resulting in high levels of anxiety and depression (Blinderman, Homel, Billings, Tennstedt, \& Portenoy, 2009; Maurer et al., 2008). The gradual disability leads to an increasing dependence on significant others, frequently the patient's spouse/partner or other family member/friend (Rodriguez Gonzalez-Moro et al., 2009; Simpson \& Rocker, 2008). In a literature review to evaluate COPD economic costs in European countries, it was found that the indirect costs, in terms of loss of productivity of both patients and family carers, accounted for the majority of total COPD costs in France (67\%), Sweden (58\%) and United Kingdom (50\%)(Nowak et al., 2005). In the United States, it was found that individuals with chronic lung disease received an additional 5.1 hours/week of informal care when compared to those without lung disease. This represents an annual cost of informal care of over $\$ 2$ billion dollars (Langa et al., 2002). These numbers indicate that families provide a vital source of care to their relatives with COPD, however, little is known about the impacts of caring on carers' everyday life and psychological well-being (Grant, Cavanagh, \& Yorke, 2012). Yet, there is growing evidence that providing care to people with COPD is a stressful experience, likely to involve significant burden (Grant et al., 2012; Simpson, Young, Donahue, \& Rocker, 2010).

The term "burden" or "carer burden" has been extensively used throughout the literature to describe the impacts of the care-giving process on the carer. Despite the multiple and inconsistent designations, there 


\section{Caring for relatives with chronic obstructive pulmonary disease: how does the disease severity impact on family carers?}

is a common used definition, proposed by George and Gwyther (1986,p.253), who described carer burden as "the physical, psychological or emotional, social and financial problems that can be experienced by family members caring for impaired older adults". This definition emphasises the multidimensional nature of the carer burden, implying that different services and interventions might be needed to provide relief and promote adjustment to the care-giving role (Charlesworth, Tzimoula, \& Newman, 2007). George and Gwyther's conceptualisation also underlines the subjective appraisal of the care-giving experience subjective burden - which, according to the transactional models of stress (Lazarus \& Folkman, 1984; Pearlin, Mullan, Semple, \& Skaff, 1990), explains much of the variability in terms of carers' health outcomes.

Decades of research on chronic diseases like dementia, cancer or stroke has provided evidence that carer's burden increases the risk of negative physical, psychological and physiological outcomes (Carretero, Garcés, Ródenas, \& Sanjosé, 2009; Savundranayagam, Montgomery, \& Kosloski, 2011). However, a number of comparative studies suggest that different chronic conditions present distinct caregiving demands, hence research needs to demarcate each disease's specificities (like COPD) from the general aspects of care-giving (Grant et al., 2012). For instance, chronic diseases characterized by cognitive impairments have been found to be more burdensome (Holmes \& Deb, 2003; Huang et al., 2009; Papastavrou, Charalambous, Tsangari, \& Karayiannis, 2012). Also, disorders with an unpredictable course (e.g., Alzheimer's disease) are more distressful than those with an expected trajectory (e.g., stroke)(Kim \& Schulz, 2008; Wright, Hickey, Buckwalter, Hendrix, \& Kelechi, 1999).

Furthermore, the disease severity has been found to predict family carer burden (Vitaliano, Russo, Young, Teri, \& Maiuro, 1991), although some studies do not support this result (Anderson, Linto, \& StewartWynne, 1995; Zarit, Todd, \& Zarit, 1986). It is supposed that the health condition of a patient with early or advanced COPD poses different demands upon carers, but this assumption remains unclear since the existing literature has focused mostly on COPD caregiving at end-of-life stages (Bergs, 2002; Currow, Ward, Clark, Burns, \& Abernethy, 2008; Garlo, O'Leary, Van Ness, \& Fried, 2010; Hynes, Stokes, \& McCarron, 2012; Kanervisto, Kaistila, \& Paavilainen, 2007; Seamark, Blake, Seamark, \& Halpin, 2004). Consequently, evidence on the care-giving experience in early grades of COPD is required. 


\section{Caring for relatives with chronic obstructive pulmonary disease: how does the disease severity impact on family carers?}

This study aimed to analyse the subjective burden of family carers of people with early and advanced COPD and its predictor variables.

\section{Methods}

\section{Design and participants}

A cross-sectional study was conducted with a convenience sample of family carers of people with COPD, between December 2010 and February 2012. Participants were included if they were: $\geq 18$ years old; the primary carer (the person who provided the largest amount of physical and/or supportive care without receiving any payment) of a relative with COPD who was living in the community; able to understand the purpose of the study and agreed to voluntarily participate in the study. Participants were excluded if they presented inability to understand and co-operate.

Family carers were recruited from two primary care centres and one district hospital in the central region of Portugal. Clinicians from these healthcare institutions were asked to identify and classify outpatients with COPD according to the Global Initiative for Chronic Obstructive Lung Disease (GOLD) criteria: early (GOLD 1 and 2) and advanced (GOLD 3 and 4) COPD (GOLD, 2013). Potentially eligible outpatients were contacted via telephone by a clinician's assistance, who informed about the study and asked their willingness to be contacted by the researchers. Interested participants received a telephone call from the researchers, were informed about the study specific objectives and were asked to identify their primary carer. Two hundred and twenty seven patients were initially approached but 7 were not able to identify their primary family carer. A total of 220 family carers were then contacted by the researchers, informed about the study purpose and invited to participate. One hundred and eighty seven agreed to participate, 33 refused as they did not perceive the relevance of the study and 20 failed to attend the meeting. The final sample consisted of 167 family carers of 167 matched patients with COPD. A meeting was then scheduled in the primary care centre or the hospital, according to participants' location. Written informed consents were obtained prior to any data collection. Data on socio-demographics, subjective burden and psychological health were collected by interview-administrated questionnaires. 


\section{Caring for relatives with chronic obstructive pulmonary disease: how does the disease severity impact on family carers?}

\section{Data collection}

Socio-demographic data and information on the care-giving situation (type of relationship with the caredfor person, care-giving period and hours of care provided per week) were collected through a structured questionnaire. Self-rated physical and mental health were measured by the two items from the International Classification of Functioning, Disability and Health checklist (World Health Organization, 2001): i) "How do you rate your physical health in the past month"; ii) "How do you rate your mental and emotional health in the past month?". Each item has the following five reply alternatives in a 5-point Likertscale: "very good” (1); “good” (2); “moderate” (3); "bad” (4); “very bad” (5).

The Portuguese version of the Hospital Anxiety and Depression Scale (HADS) (Pais-Ribeiro et al., 2007) was used to assess carers' anxiety and depression symptoms. HADS is a 14-item questionnaire which measures both anxiety (HADS-A) and depression (HADS-D) on two separate 7-items subscales, ranging from 0 (minimum symptom load) to 21 (maximum symptom load). A score $\geq 8$ in the HADS-A/HADS-D was used to consider the presence of anxiety and depression symptoms (Bjelland, Dahl, Haug, \& Neckelmann, 2002). HADS has been internationally reported as a valid and reliable instrument (Herrmann, 1997) and the psychometric properties of the Portuguese version were also found to be similar to those in international studies (Pais-Ribeiro et al., 2007).

The Portuguese version of the Carers' Assessment of Difficulties Index (CADI) (Brito, 2002) was used to assess subjective burden as it has been considered an appropriate instrument for the assessment of the multidimensional burden of carers (Charlesworth et al., 2007). The original version of CADI was developed by Nolan et al. (Nolan \& Grant, 1989; Nolan, Grant, \& Ellis, 1990). CADI consists of 30 items comprising 7 subscales: carer-dependent relationships, reactions to care-giving, physical demands of caring, restricted social life, poor family support, poor professional support and financial consequences. For each item, participants indicated in a 4-point Likert-scale if the statement: "does not apply" (0); "applies, but not stressful" (1); "applies and finds it quite stressful" (2); or "applies and finds it very stressful" (3). Higher scores are indicative of greater subjective burden. CADI has presented high internal consistency with a Cronbach's alpha coefficient of .92 for both the original version (Nolan, Grant, \& Keady, 


\section{Caring for relatives with chronic obstructive pulmonary disease: how does the disease severity impact on family carers?}

1998) and the Portuguese version (Brito, 2002). To our knowledge, the CADI has not been previously used with COPD care-giving population. Thus, a pilot test to analyse the internal consistency and testretest reliability was performed. For global CADI and sub-scales, moderate to high internal consistency (Cronbach's alpha coefficients ranged from .56 to .87 ) and almost perfect test-retest reliability (Intraclass Correlation Coefficients ranged from .67 to .98) were found (George \& Mallery, 2003; Landis \& Koch, 1977).

All instruments were administrated in a face-to-face interview conducted by two trained researchers. The interviews lasted approximately 40 minutes.

\section{Ethical considerations}

The study received full approval from the Ethics Committees of the Centre Health Regional Administration (Portugal) and of the São Sebastião Hospital (Portugal).The family carers who participated in this study were unpaid volunteers.

\section{Data analysis}

Descriptive statistics were used to characterise the groups (family carers of people with early COPD vs. advanced COPD) and analyse the frequency of each CADI item. Inferential statistics were used to compare groups' characteristics: independent t-tests for continuous, Chi-square tests for categorical and Mann-Whitney U-test for ordinal variables. Effect sizes were also calculated using the Cohen's d, the Cramer's $\mathrm{V}$ and the effect size estimates for the Mann-Whitney U-test, respectively (Fritz, Morris, \& Richler, 2012). An independent t-test was used to analyse differences between groups regarding CADI global score. To compare the frequency distributions of each CADI item, the original 4-point Likert-scale was recoded into "not stressful" ("does not apply" and "applies, but not stressful") and "stressful" ("applies and finds it quite stressful" and "applies and finds it very stressful") and Chi-square tests were performed. Bivariate associations between CADI and COPD severity, care-giving hours per week, anxiety/depression scores and self-rated health were analysed through Spearman's correlation coefficient. Variables with significant associations in this univariate analysis and socio-demographic variables (gender, age and 


\section{Caring for relatives with chronic obstructive pulmonary disease: how does the disease severity impact on family carers?}

academic qualifications) were included in a multiple linear regression model to predict the CADI global score. A p $<0.05$ was considered as statistically significant for all tests. All statistical analyses were performed using PAWS Statistics (Version 18.0, SPSS Inc., Chicago, IL).

\section{Results}

\section{Participants' characteristics}

A total of 167 family carers were included in the study: 113 caring for relatives with early COPD (mean age $58.3 \pm 12.7$ years) and 54 caring for relatives with advanced COPD (mean age 60.5 \pm 13.9 years) (Table 1). Patients with COPD were predominantly men $(n=107 ; 64.1 \%)$, with a mean age of $69.3 \pm 11.5$ years old. Family carers were mostly women, however male carers were more common in the early rather than advanced COPD group $(p=0.033)$. Most carers were married, had low educational qualifications, were retired or had a full time employment. Family carers were predominantly spouses and were caring for more than 4 years. The hours spent per week in care-giving tasks were higher in those caring for advanced COPD $(p=0.001)$.

Anxiety symptoms were observed in $61.9 \%(n=70)$ of family carers of people with early COPD and in $70.4 \%(n=39)$ of those caring at advanced COPD $(p=0.290)$. Depression symptoms were significantly more frequent in family carers of people with advanced COPD $(p=0.030)$. Self-rated physical $(p=0.035)$ and mental $(p=0.011)$ health were significantly worse in carers of people with advanced COPD when compared to those caring for people with early COPD (Table 1).

(Table 1)

\section{Subjective burden}

The overall CADI score was significantly higher in family carers of people with advanced COPD than in carers of people with early COPD (22.0 vs. 11.2; $\mathrm{p}=0.001)$. A more detailed comparative analysis on the perceived difficulties is presented in table 2. The items rated as most stressful by family carers of people with early COPD were "feeling helpless/not in control of the situation" $\left(1^{\text {st }}\right)$, "sleep affected" $\left(2^{\text {nd }}\right)$, "financial 


\section{Caring for relatives with chronic obstructive pulmonary disease: how does the disease severity impact on family carers?}

difficulties" / "standard of living fallen" $\left(3^{\text {rd }}\right)$. For family carers of people with advanced COPD, "feeling helpless/not in control of the situation" was also perceived as the most stressful aspect of caring, followed by "feelings of being manipulated by the cared-for person" $\left(2^{\text {nd }}\right)$ and "emotional well-being suffering" $\left(3^{\text {rd }}\right)$. Although the majority of CADI items were rated as not applicable by more than $50 \%$ of the participants, several statistically significant differences were found between the two groups. Most items considered in "carer-dependent relationship", "reactions to care-giving", "physical demands of caring" and "restrictions in social life" subscales were significantly more perceived as stressful by family carers of people with advanced COPD. "Poor professional support" was the only subscale for which significant differences were not found.

(Table 2)

\section{Predictors of subjective burden}

CADI global score was significantly associated with all variables (Table 3): higher subjective burden was associated with severe COPD, more care-giving hours per week, higher anxiety/depression symptoms and worse self-rated health. All the CADI subscales were correlated with all the considered variables, with the exception of the "restricted social life", "poor family support" and "poor professional support".

(Table 3)

A multiple linear regression was performed to predict carers' subjective burden (CADI global score) using the variables from table 3 with probability values of $p<0.05$, together with the socio-demographic variables. Advanced COPD (Coefficient 6.7; $p=0.003$ ), depression (Coefficient 6.3; $p=0.008$ ), anxiety (Coefficient 5.6; $p=0.017$ ), care-giving hours per week (Coefficient 3.2; $p=0.001$ ) and self-rated mental health (Coefficient 2.8; $p=0.029$ ) were retained in the model and were independent predictors of the carers' subjective burden. This regression model predicted $33 \%(p<0.001)$ of total variation of the CADI global score.

\section{Discussion}




\section{Caring for relatives with chronic obstructive pulmonary disease: how does the disease severity impact on family carers?}

Family carers of people with advanced COPD experienced more often and found more stressful the majority of CADI items than those caring for early COPD. Carers of advanced COPD also reported higher depression symptoms and a worse self-rated mental health. Moreover, COPD severity was found to be a significant predictor of the carers' subjective burden, contrarily to the results from previous studies (Pinto, Holanda, Medeiros, Mota, \& Pereira, 2007; Ross \& Graydon, 1997). Methodological reasons might explain these differences, as previous studies presented relative small sample sizes.

In contrast, the frequency of anxiety symptoms was similar in both groups, underlying the uncertain and unpredictable nature of the disease (Boyle, 2009). The COPD course has relatively stable periods of different length, which are often interrupted by episodes of flare-up or acute exacerbations (Rolland, 1994). Strain on the family system, particularly on carers, might be originated by both the frequency of transitions between crisis and non-crisis periods and the ongoing uncertainty of when an exacerbation will occur and how it will end (Boyle, 2009; Rolland, 1994)

The statistically significant differences between groups concerning "carer-dependent relationship", "reactions to care-giving", "physical demands of caring" and "restricted social life" suggests that the progressive and incapacitating nature of COPD might be burdensome. Carers' feelings of being manipulated, lack of patient's appreciation for their care efforts and resistance to care have been earlier reported as negative impacts on carer-patient relationship. This may be due to the increasing frustration, emotional liability, irritability and mood disturbances, more likely to occur in those living with advanced COPD (Bergs, 2002; Seamark et al., 2004; Simpson et al., 2010). Furthermore, "carer-dependent relationship" subscale was significantly correlated with depression, anxiety and self-rated mental health among carers of people with COPD. These results suggest that a strained caring relationship significantly affects the carer psychological well-being. Similar findings were found by Fried et al. and Pinto et al., sustaining the need of early interventions to support the care-giving and-receiving relational process (Fried, Bradley, O'Leary, \& Byers, 2005; Pinto et al., 2007). Despite the relational difficulties, both groups were able to find meaning and gratification in the care-giving relationship. This is in line with recent research, which suggests that positive aspects of caring often co-exist with difficulties (Janssen, Spruit, Wouters, \& Schols, 2012). Thus, professional efforts to help carers to find meaning in their care role 


\section{Caring for relatives with chronic obstructive pulmonary disease: how does the disease severity impact on family carers?}

should be encouraged as this has been associated with improved carer well-being, successful coping and attitude towards future (Nolan et al., 1998; Tarlow et al., 2004).

Negative emotional "reactions to care-giving" were also more stressful for carers of people with advanced COPD, and were significantly associated with higher depression and anxiety scores and with worse selfrated mental health. "Feelings of helplessness/loss of control of the situation" was the most stressful situation commonly reported by both groups, with no statistically significant differences observed. As stated before, the unpredictable nature of the disease might explain this result.

"Physical demands of caring" and "restrictions in social life" were also perceived as the most stressful by carers of people with advanced COPD. The results are not surprising, since as the disease progresses, the workload and responsibilities also tend to increase (e.g., monitoring breathlessness, medications, long-term oxygen therapy, helping with personal care), reducing carers' ability to engage in social activities (Boyle, 2009; Gullick, 2012; Simpson et al., 2010). Moreover, the hours spent per week in caregiving tasks were a significant predictor of the carers' subjective burden. Such findings underline the importance to support carers with physical care, symptom control and useful information about the disease prognosis, earlier in the disease trajectory. Carers' needs are generally unmet by the health and social care services (Bergs, 2002; Currow et al., 2008; Gullick, 2012; Simpson et al., 2010). Thus, raising community awareness for the availability of respite services is fundamental to prevent fatigue, preserve personal freedom and enable self-care (Simpson et al., 2010).

Significant correlations between "financial consequences" and anxiety/depression scores and self-rated health were found, sustaining the stressful nature of financial implications of COPD. Financial strain is mainly related to expensive medication, oxygen therapy, alongside with the loss of care recipient's income due to early retirement forced by the disease (Simpson et al., 2010). This highlights the need for financial support.

"Poor professional support" was the unique subscale for which no statistically significant differences were found. Moreover, the listed caring situations were rated as "not applicable" in about $80 \%$ of each subsample, suggesting that participants perceived as adequate the professional support given from services, 


\section{Caring for relatives with chronic obstructive pulmonary disease: how does the disease severity impact on family carers?}

which in part contradicts previous research (Currow et al., 2008; Grant et al., 2012; Spence et al., 2008). Easier access to oxygen-related resources, support with symptom control and physical care, diseasespecific information, emotional support and skills training have been earlier reported as carers' unmet needs (Currow et al., 2008; Simpson et al., 2010). Cultural reasons might explain our findings, as pulmonary rehabilitation for patients and supportive interventions for families (e.g., respite, psychoeducation, mutual support groups) are not widespread in Portugal. Hence, families do not have expectations about what they can be offered by health and social services. Patient and family's contacts with services consist mainly of visits to general practitioners in primary care or emergency admissions to hospitals for acute COPD exacerbations.

Some limitations need to be acknowledged. The total sample consisted of two cohorts with significant differences in their socio-demographic characteristics in terms of gender and the care-giving hours. These differences, alongside with the disease severity, might also account to explain the results among early and advanced COPD. Studies with larger samples controlled for socio-demographic and care-giving involvement variables should be conducted to clarify these findings. The majority of CADI items were rated as "not applicable" in more than $50 \%$ of the participants, suggesting that, despite its good psychometric properties, the relevance of CADI items in COPD caring experience might be questionable. In fact, the care of people with COPD presents particular challenges - such as the management of complex therapy technologies, multiple medication regimens and treatments for symptom control, or even restricted communication between the carer and the patient due to the patient's shortness of breath (Grant et al., 2012) - that might distinguish COPD care-giving experience from the caring of other chronic conditions for which CADI has been applied (Charlesworth et al., 2007; Knussen, Tolson, Swan, Stott, \& Brogan, 2005; Mafullul, 2002; Rowbotham, Carroll, \& Cuskelly, 2011; Rowbotham, Cuskelly, \& Carroll, 2011; Wennerberg, Lundgren, \& Danielson, 2012). Thus, the psychometric properties of CADI should be further explored in carers of people with COPD. Despite the comparison, the cross-sectional design is limited to provide consistent data on the changing nature of care-giving demands along with the course of COPD. Future research needs to follow family carers over time and examine the changes in subjective 


\section{Caring for relatives with chronic obstructive pulmonary disease: how does the disease severity impact on family carers?}

burden across the course of COPD. This information is crucial for planning adequate and successful interventions in the community to support COPD carers in their role and prevent burden.

Nonetheless, the current study contributes significantly to the research world by providing unique knowledge about COPD carers' difficulties at early and advanced grades of the disease. The findings suggest that care-giving overall subjective burden is associated with poorer self-rated health and psychological well-being. However, despite growing research evidence and international concern about the negative impacts of caring on carers' overall health (Organisation for Economic Co-operation and Development, 2011; World Health Organization, 2002), interventions designed to support COPD carers have not been developed(Caress, Luker, Chalmers, \& Salmon, 2009; Grant et al., 2012). Research on the effectiveness of support interventions tailored to the specific demands of COPD care-giving, and delivered earlier in the care-giving trajectory, is required.

\section{Acknowledgements}

The authors would like to acknowledge all institutions and carers involved for their participation in this research. This work was supported by Portuguese National Funds through FCT - Foundation for Science and Technology [Grant number RIPD/CIF/109502/2009].

\section{References}

Anderson, C. S., Linto, J., \& Stewart-Wynne, E. G. (1995). A population-based assessment of the impact and burden of caregiving for long-term stroke survivors. Stroke, 26(5), 843-849.

Barnett, M. (2005). Chronic obstructive pulmonary disease: a phenomenological study of patients' experiences. Journal of Clinical Nursing, 14(7), 805-812.

Bergs, D. (2002). 'The Hidden Client'- women caring for husbands with COPD: their experience of quality of life. Journal of Clinical Nursing, 11(5), 613-621.

Bjelland, I., Dahl, A. A., Haug, T. T., \& Neckelmann, D. (2002). The validity of the Hospital Anxiety and Depression Scale. An updated literature review. J Psychosom Res, 52(2), 69-77. 


\section{Caring for relatives with chronic obstructive pulmonary disease: how does the disease severity impact on family carers?}

Blinderman, C. D., Homel, P., Billings, J. A., Tennstedt, S., \& Portenoy, R. K. (2009). Symptom Distress and Quality of Life in Patients with Advanced Chronic Obstructive Pulmonary Disease. Journal of Pain and Symptom Management, 38(1), 115-123.

Boyle, A. (2009). An integrative review of the impact of COPD on families. Southern Online Journal of Nursing Research, 9(3), 1-12.

Brito, L. (2002). A Saúde Mental dos Prestadores de Cuidados a Familiares Idosos. Coimbra: Quarteto Editora.

Caress, A.-L., Luker, K. A., Chalmers, K. I., \& Salmon, M. P. (2009). A review of the information and support needs of family carers of patients with chronic obstructive pulmonary disease. Journal of Clinical Nursing, 18(4), 479-491.

Carretero, S., Garcés, J., Ródenas, F., \& Sanjosé, V. (2009). The informal caregiver's burden of dependent people: Theory and empirical review. Archives of Gerontology and Geriatrics, 49(1), 74-79.

Charlesworth, G. M., Tzimoula, X. M., \& Newman, S. P. (2007). Carers Assessment of Difficulties Index (CADI): psychometric properties for use with carers of people with dementia. Aging \& Mental Health, 11(2), 218-225.

Currow, D. C., Ward, A., Clark, K., Burns, C. M., \& Abernethy, A. P. (2008). Caregivers for people with end-stage lung disease: characteristics and unmet needs in the whole population. International journal of chronic obstructive pulmonary disease, 3(4), 753-762.

Fried, T. R., Bradley, E. H., O'Leary, J. R., \& Byers, A. L. (2005). Unmet Desire for Caregiver-Patient Communication and Increased Caregiver Burden. Journal of the American Geriatrics Society, 53(1), 59-65.

Fritz, C. O., Morris, P. E., \& Richler, J. J. (2012). Effect size estimates: current use, calculations, and interpretation. Journal of Experimental Psychology: General, 141(1), 2-18.

Gardiner, C., Gott, M., Payne, S., Small, N., Barnes, S., Halpin, D., . . Seamark, D. (2010). Exploring the care needs of patients with advanced COPD: An overview of the literature. Respiratory Medicine, 104(2), 159-165. 


\section{Caring for relatives with chronic obstructive pulmonary disease: how does the disease severity impact on family carers?}

Garlo, K., O'Leary, J. R., Van Ness, P. H., \& Fried, T. R. (2010). Burden in Caregivers of Older Adults with Advanced Illness. Journal of the American Geriatrics Society, 58(12), 2315-2322.

George, D., \& Mallery, P. (2003). SPSS for Windows step by step: A simple guide and reference.11.0 update (4th ed.). Boston: Allyn \& Bacon.

George, L. K., \& Gwyther, L. P. (1986). Caregiver Well-Being: A Multidimensional Examination of Family Caregivers of Demented Adults. The Gerontologist, 26(3), 253-259.

GOLD. (2013). Global Initiative for Chronic Obstructive Lung Disease. Global Strategy for the Diagnosis, Management and Prevention of COPD Available from: http://www.goldcopd.orgl.

Grant, M., Cavanagh, A., \& Yorke, J. (2012). The impact of caring for those with chronic obstructive pulmonary disease (COPD) on carers' psychological well-being: A narrative review. International Journal of Nursing Studies, 49(11), 1459-1471.

Gullick, J. (2012). Psychosocial dimensions of COPD for the patient and family. In Kian-Chung Ong (Ed.), Chronic Pbstructive Pulmonary Disease: Current Concepts and Practice (pp. 153-178). Rijeka: InTech.

Halbert, R. J., Natoli, J. L., Gano, A., Badamgarav, E., Buist, A. S., \& Mannino, D. M. (2006). Global burden of COPD: systematic review and meta-analysis. European Respiratory Journal, 28(3), 523-532.

Herrmann, C. (1997). International experiences with the Hospital Anxiety and Depression Scale-A review of validation data and clinical results. Journal of Psychosomatic Research, 42(1), 17-41.

Holmes, A. M., \& Deb, P. (2003). The effect of chronic illness on the psychological health of family members. J Ment Health Policy Econ, 6(1), 13-22.

Huang, C. Y., Sousa, V. D., Perng, S. J., Hwang, M. Y., Tsai, C. C., Huang, M. H., \& Yao, S. Y. (2009). Stressors, social support, depressive symptoms and general health status of Taiwanese caregivers of persons with stroke or Alzheimer's disease. J Clin Nurs, 18(4), 502-511.

Hynes, G., Stokes, A., \& McCarron, M. (2012). Informal care-giving in advanced chronic obstructive pulmonary disease: lay knowledge and experience. Journal of Clinical Nursing, 21(7-8), 10681077. 


\section{Caring for relatives with chronic obstructive pulmonary disease: how does the disease severity impact on family carers?}

Janssen, D. J. A., Spruit, M. A., Wouters, E. F. M., \& Schols, J. M. G. A. (2012). Family Caregiving in Advanced Chronic Organ Failure. Journal of the American Medical Directors Association, 13(4), 394-399.

Kanervisto, M., Kaistila, T., \& Paavilainen, E. (2007). Severe chronic obstructive pulmonary disease in a family's everyday life in Finland: Perceptions of people with chronic obstructive pulmonary disease and their spouses. Nursing \& Health Sciences, 9(1), 40-47.

Kim, Y., \& Schulz, R. (2008). Family Caregivers' Strains: Comparative Analysis of Cancer Caregiving With Dementia, Diabetes, and Frail Elderly Caregiving. Journal of Aging and Health, 20(5), 483-503.

Knussen, C., Tolson, D., Swan, I. R. C., Stott, D. J., \& Brogan, C. A. (2005). Stress proliferation in caregivers: The relationships between caregiving stressors and deterioration in family relationships. Psychology \& Health, 20(2), 207-221.

Landis, J. R., \& Koch, G. G. (1977). The measurement of observer agreement for categorical data. Biometrics, 33(1), 159-174.

Langa, K. M., Fendrick, A. M., Flaherty, K. R., Martinez, F. J., Kabeto, M. U., \& Saint, S. (2002). Informal caregiving for chronic lung disease among older Americans. Chest, 122(6), 2197-2203.

Lazarus, R. S., \& Folkman, S. (1984). Stress, Appraisal, and Coping. New York: Springer.

Mafullul, Y. M. (2002). Burden of informal carers of mentally infirm eldery in Lancashire. East African medical journal, 79(6), 291-298.

Mannino, D. M., \& Braman, S. (2007). The Epidemiology and Economics of Chronic Obstructive Pulmonary Disease. Proceedings of the American Thoracic Society, 4(7), 502-506.

Maurer, J., Rebbapragada, V., Borson, S., Goldstein, R., Kunik, M. E., Yohannes, A. M., \& Hanania, N. A. (2008). Anxiety and Depression in COPD. Chest, 134(4 suppl), 43S-56S.

Nolan, M. R., \& Grant, G. (1989). Addressing the needs of informal carers: a neglected area o nursing practice. Journal of Advanced Nursing, 14(11), 950-961.

Nolan, M. R., Grant, G., \& Ellis, N. C. (1990). Stress is in the eye of the beholder: reconceptualizing the measurement of carer burden. Journal of Advanced Nursing, 15(5), 544-555. 


\section{Caring for relatives with chronic obstructive pulmonary disease: how does the disease severity impact on family carers?}

Nolan, M. R., Grant, G., \& Keady, J. (1998). Assessing Carer's Needs: A Practitioner's Guide. Brighton: Pavilion Publications.

Nowak, D., Berger, K., Lippert, B., Kilgert, K., Caeser, M., \& Sandtmann, R. (2005). Epidemiology and health economics of COPD across Europe: a critical analysis. Treat Respir Med, 4(6), 381-395.

Organisation for Economic Co-operation and Development. (2011). Help Wanted? Providing and Paying for Long-Term Care.

Pais-Ribeiro, J., Silva, I., Ferreira, T., Martins, A., Meneses, R., \& Baltar, M. (2007). Validation study of a Portuguese version of the Hospital Anxiety and Depression Scale. Psychology, Health and Medicine, 12(2), 225-237.

Papastavrou, E., Charalambous, A., Tsangari, H., \& Karayiannis, G. (2012). The burdensome and depressive experience of caring: what cancer, schizophrenia, and Alzheimer's disease caregivers have in common. Cancer Nurs, 35(3), 187-194.

Pauwels, R. A., \& Rabe, K. F. (2004). Burden and clinical features of chronic obstructive pulmonary disease (COPD). Lancet, 364(9434), 613-620.

Pearlin, L. I., Mullan, J. T., Semple, S. J., \& Skaff, M. M. (1990). Caregiving and the Stress Process: An Overview of Concepts and Their Measures. The Gerontologist, 30(5), 583-594.

Pinto, R. A., Holanda, M. A., Medeiros, M. M. C., Mota, R. M. S., \& Pereira, E. D. B. (2007). Assessment of the burden of caregiving for patients with chronic obstructive pulmonary disease. Respiratory medicine, 101(11), 2402-2408.

Rodriguez Gonzalez-Moro, J. M., De Lucas Ramos, P., Izquierdo Alonso, J. L., López-Muñiz Ballesteros, B., Antón Díaz, E., Ribera, X., \& Martín, A. (2009). Impact of COPD severity on physical disability and daily living activities: EDIP-EPOC I and EDIP-EPOC II studies. International Journal of Clinical Practice, 63(5), 742-750.

Rolland, J. S. (1994). Families, illness, and disability: An integrative treatment model. New York: Basic Books.

Ross, E., \& Graydon, J. E. (1997). The impact on the wife of caring for a physically ill spouse. Journal of Women \& Aging, 9(4), 23-35. 


\section{Caring for relatives with chronic obstructive pulmonary disease: how does the disease severity impact on family carers?}

Rowbotham, M., Carroll, A., \& Cuskelly, M. (2011). Mothers' and Fathers' Roles in Caring for an Adult Child with an Intellectual Disability. International Journal of Disability, Development and Education, 58(3), 223-240.

Rowbotham, M., Cuskelly, M., \& Carroll, A. (2011). Sustainable caregiving? Demands upon and resources of female carers of adults with intellectual disability. Journal of Women \& Aging, 23(2), 129-148.

Savundranayagam, M. Y., Montgomery, R. J. V., \& Kosloski, K. (2011). A Dimensional Analysis of Caregiver Burden Among Spouses and Adult Children. The Gerontologist, 51(3), 321-331.

Seamark, D. A., Blake, S. D., Seamark, C. J., \& Halpin, D. M. (2004). Living with severe chronic obstructive pulmonary disease (COPD): perceptions of patients and their carers. Palliative Medicine, 18(7), 619-625.

Simpson, A. C., \& Rocker, G. M. (2008). Advanced chronic obstructive pulmonary disease: rethinking models of care. QJM: monthly journal of the Association of Physicians, 101(9), 697-704.

Simpson, A. C., Young, J., Donahue, M., \& Rocker, G. (2010). A day at a time: caregiving on the edge in advanced COPD. International journal of chronic obstructive pulmonary disease, 5(1), 141-151.

Spence, A., Hasson, F., Waldron, M., Kernohan, G., McLaughlin, D., Cochrane, B., \& Watson, B. (2008). Active carers: living with chronic obstructive pulmonary disease. International journal of palliative nursing, 14(8), 368-372.

Tarlow, B. J., Wisniewski, S. R., Belle, S. H., Rubert, M., Ory, M. G., \& Gallagher-Thompson, D. (2004). Positive Aspects of Caregiving: Contributions of the REACH Project to the Development of New Measures for Alzheimer's Caregiving. Research on Aging, 26(4), 429-453.

Vitaliano, P. P., Russo, J., Young, H. M., Teri, L., \& Maiuro, R. D. (1991). Predictors of burden in spouse caregivers of individuals with Alzheimer's disease. Psychol Aging, 6(3), 392-402.

Wennerberg, M. M. T., Lundgren, S. M., \& Danielson, E. (2012). Using the salutogenic approach to unravel informal caregivers' resources to health: Theory and methodology. Aging \& Mental Health, 16(3), 391-402.

World Health Organization. (2001). ICF Checklist Version 2.1a, Clinical Form for International Classification of Functioning, Disability and Health. Geneva: World Health Organization,. 
Caring for relatives with chronic obstructive pulmonary disease: how does the disease severity impact on family carers?

World Health Organization. (2002). Active aging: a policy framework. Geneva: WHO.

Wright, L. K., Hickey, J. V., Buckwalter, K. C., Hendrix, S. A., \& Kelechi, T. (1999). Emotional and physical health of spouse caregivers of persons with Alzheimer's disease and stroke. J Adv Nurs, 30(3), 552-563.

Zarit, S. H., Todd, P. A., \& Zarit, J. M. (1986). Subjective burden of husbands and wives as caregivers: a longitudinal study. Gerontologist, 26(3), 260-266. 
Caring for relatives with chronic obstructive pulmonary disease: how does the disease severity

impact on family carers?

Table 1 - Socio-demographics, caregiving characteristics, self-rated health, anxiety and depression of carers of people at early and advanced COPD ( $n=167)$.

\begin{tabular}{|c|c|c|c|c|}
\hline Characteristics & $\begin{array}{l}\text { Early COPD } \\
(n=113)\end{array}$ & $\begin{array}{l}\text { Advanced COPD } \\
(n=54)\end{array}$ & $\mathbf{p}$ & $\begin{array}{l}\text { Effect } \\
\text { size }\end{array}$ \\
\hline Age (years) $\mathrm{m} \pm \mathrm{SD}$ (min-max) & $58.3 \pm 12.7(26-80)$ & $60.5 \pm 13.9(21-81)$ & 0.317 & 0.160 \\
\hline \multicolumn{5}{|l|}{ Gender n(\%) } \\
\hline Female & $79(69.9 \%)$ & $46(85.2 \%)$ & \multirow[t]{2}{*}{0.033} & \multirow[t]{2}{*}{0.165} \\
\hline Male & $34(30.1 \%)$ & $8(14.8 \%)$ & & \\
\hline \multicolumn{5}{|l|}{ Academic qualifications $n(\%)$} \\
\hline No qualifications & $12(10.6 \%)$ & $7(13.0 \%)$ & \multirow[t]{5}{*}{0.191} & \multirow[t]{5}{*}{0.191} \\
\hline 1st cycle & $39(34.5 \%)$ & $27(50.0 \%)$ & & \\
\hline 2nd cycle & $21(18.6 \%)$ & $7(13.0 \%)$ & & \\
\hline 3rd cycle & $14(12.4 \%)$ & $7(13.0 \%)$ & & \\
\hline Secondary/Higher school & $27(23.9 \%)$ & $6(11.0 \%)$ & & \\
\hline \multicolumn{5}{|l|}{ Work status n(\%) } \\
\hline Full-time employment & $35(31.0 \%)$ & $16(29.6 \%)$ & \multirow[t]{5}{*}{0.994} & \multirow[t]{5}{*}{0.037} \\
\hline Retirement & $54(47.8 \%)$ & $25(46.3 \%)$ & & \\
\hline Unemployment & $12(10.6 \%)$ & $7(13.0 \%)$ & & \\
\hline Domestic & $10(8.8 \%)$ & $5(9.2 \%)$ & & \\
\hline Student & $2(1.8 \%)$ & $1(1.9 \%)$ & & \\
\hline \multicolumn{5}{|l|}{ Marital Status n(\%) } \\
\hline Married & $93(82.4 \%)$ & $46(85.1 \%)$ & \multirow[t]{4}{*}{0.899} & \multirow[t]{4}{*}{0.065} \\
\hline Single & $10(8.8 \%)$ & $5(9.3 \%)$ & & \\
\hline Divorced & $6(5.3 \%)$ & $2(3.7 \%)$ & & \\
\hline Widowed & $4(3.5 \%)$ & $1(1.9 \%)$ & & \\
\hline \multicolumn{5}{|c|}{ Relationship with cared for person $\mathrm{n}(\%)$} \\
\hline Spouse & $72(63.7 \%)$ & $33(61.1 \%)$ & \multirow{4}{*}{0.876} & \multirow[t]{4}{*}{0.064} \\
\hline Daughter/son & $30(26.5 \%)$ & $14(25.9 \%)$ & & \\
\hline Brother/sister & $2(1.8 \%)$ & $2(3.7 \%)$ & & \\
\hline Others & $9(8.0 \%)$ & $5(9.3 \%)$ & & \\
\hline \multicolumn{5}{|l|}{ Caregiving period (years) $n(\%)$} \\
\hline Less than 1 & $12(10.6 \%)$ & $4(7.4 \%)$ & \multirow[t]{4}{*}{0.239} & \multirow[t]{4}{*}{0.159} \\
\hline $1-2$ & $11(9.7 \%)$ & $3(5.6 \%)$ & & \\
\hline $2-4$ & $27(23.9 \%)$ & $8(14.8 \%)$ & & \\
\hline More than 4 & $63(55.8 \%)$ & $39(72.2 \%)$ & & \\
\hline \multicolumn{5}{|l|}{ Caregiving hours per week n(\%) } \\
\hline $0-8 \mathrm{~h}$ & $52(46.0 \%)$ & $13(24.0 \%)$ & \multirow[t]{4}{*}{0.001} & \multirow[t]{4}{*}{0.332} \\
\hline $8-20 h$ & $25(22.1 \%)$ & $17(31.5 \%)$ & & \\
\hline 20-40h & $28(24.8 \%)$ & $9(16.7 \%)$ & & \\
\hline$>40 \mathrm{~h}$ & $8(7.1 \%)$ & $15(27.8 \%)$ & & \\
\hline Anxiety n(\%) & $70(61.9 \%)$ & $38(70.4 \%)$ & 0.290 & 0.082 \\
\hline Depression n(\%) & $33(29.2 \%)$ & $25(46.3 \%)$ & 0.030 & 0.168 \\
\hline Self-rated physical health $M[I Q R]$ & $3[2,3]$ & $3[3,3]$ & 0.035 & 0.164 \\
\hline Self-rated mental health $M[I Q R]$ & $3[2,3]$ & $3[2,4]$ & 0.011 & 0.198 \\
\hline
\end{tabular}

Notes: df, degrees of freedom; m, mean; SD, standard deviation; min, minimum; max, maximum; M, median; IQR, interquartile range [p25, p75]. 


\section{Caring for relatives with chronic obstructive pulmonary disease: how does the disease severity \\ impact on family carers?}

Table 2 - Comparison of Carers' Assessment of Difficulties Index (CADI) by subscales ( $n=167)$.

\begin{tabular}{|c|c|c|c|c|c|c|c|c|c|c|}
\hline \multirow{3}{*}{ Difficulties } & \multicolumn{3}{|c|}{ Early COPD $(n=113)$} & \multicolumn{5}{|c|}{ Advanced COPD $(n=54)$} & \multirow{3}{*}{$\chi^{2}$} & \multirow{3}{*}{$\mathbf{p}$} \\
\hline & \multicolumn{2}{|c|}{ Not stressful } & \multirow{2}{*}{$\begin{array}{l}\text { Stressful } \\
\text { Quite/very } \\
\text { stressful }\end{array}$} & \multirow{2}{*}{$\begin{array}{l}\text { Ranking } \\
\text { position }\end{array}$} & \multicolumn{2}{|c|}{ Not stressful } & \multirow{2}{*}{$\begin{array}{l}\text { Stressful } \\
\text { Quite/very } \\
\text { stressful }\end{array}$} & \multirow{2}{*}{$\begin{array}{l}\text { Ranking } \\
\text { position }\end{array}$} & & \\
\hline & $\begin{array}{l}\text { Does not } \\
\text { apply to me }\end{array}$ & $\begin{array}{l}\text { Applies but } \\
\text { is not } \\
\text { stressful }\end{array}$ & & & $\begin{array}{l}\text { Does not } \\
\text { apply to me }\end{array}$ & $\begin{array}{l}\text { Applies but } \\
\text { is not } \\
\text { stressful }\end{array}$ & & & & \\
\hline \multicolumn{11}{|l|}{ Carer-dependent relationship } \\
\hline $\begin{array}{l}\text { 5. The person I care for sometimes } \\
\text { manipulates me. }\end{array}$ & $85(75.2 \%)$ & $12(10.6 \%)$ & $16(14.2 \%)$ & 8 & $28(51.9 \%)$ & 0 & $26(48.1 \%)$ & 2 & 22.423 & 0.001 \\
\hline $\begin{array}{l}\text { 11. The person I care for can demand } \\
\text { too much of me. }\end{array}$ & $95(84.1 \%)$ & $5(4.4 \%)$ & $13(11.5 \%)$ & 11 & $36(66.7 \%)$ & $4(7.4 \%)$ & $14(25.9 \%)$ & 13 & 5.607 & 0.018 \\
\hline $\begin{array}{l}\text { 12. I no longer have a meaningful } \\
\text { relationship with the person I care for. }\end{array}$ & $103(91.2 \%)$ & $5(4.4 \%)$ & $5(4.4 \%)$ & 16 & $49(90.7 \%)$ & 0 & $5(9.3 \%)$ & 20 & 1.517 & 0.218 \\
\hline $\begin{array}{l}\text { 14. The person I care for doesn't always } \\
\text { help as much as they could. }\end{array}$ & $98(86.7 \%)$ & $5(4.4 \%)$ & $10(8.8 \%)$ & 13 & $33(61.1 \%)$ & $7(13.0 \%)$ & $14(25.9 \%)$ & 13 & 8.658 & 0.003 \\
\hline $\begin{array}{l}\text { 22. The person I care for doesn't } \\
\text { appreciate what I do. }\end{array}$ & $98(86.7 \%)$ & $8(7.1 \%)$ & $7(6.2 \%)$ & 15 & $37(68.5 \%)$ & $1(1.9 \%)$ & $16(29.6 \%)$ & 11 & 16.898 & 0.001 \\
\hline $\begin{array}{l}25 \text {. The behaviour of the person I care } \\
\text { for is a problem. }\end{array}$ & $98(86.7 \%)$ & $6(5.3 \%)$ & $9(8.0 \%)$ & 14 & $37(68.5 \%)$ & $2(3.7 \%)$ & $15(27.8 \%)$ & 12 & 11.656 & 0.001 \\
\hline $\begin{array}{l}26 . \text { There is no satisfaction to be gained } \\
\text { from caring. }\end{array}$ & $110(97.3 \%)$ & $1(0.9 \%)$ & $2(1.8 \%)$ & 18 & $48(88.9 \%)$ & $3(5.6 \%)$ & $3(5.6 \%)$ & 21 & 1.803 & 0.179 \\
\hline \multicolumn{11}{|l|}{ Reactions to caregiving } \\
\hline 1. I don't have any time for myself. & $87(77.0 \%)$ & $14(12.4 \%)$ & $12(10.6 \%)$ & 12 & $35(64.8 \%)$ & $2(3.7 \%)$ & $17(31.5 \%)$ & 10 & 11.082 & 0.001 \\
\hline $\begin{array}{l}\text { 2. I sometimes feel helpless/not in } \\
\text { control of the situation. }\end{array}$ & $62(54.9 \%)$ & $8(7.1 \%)$ & $43(38.1 \%)$ & 1 & $19(35.2 \%)$ & $8(14.8 \%)$ & $27(50.0 \%)$ & 1 & 2.142 & 0.143 \\
\hline $\begin{array}{l}\text { 9. It can put a strain on family } \\
\text { relationships. }\end{array}$ & $94(83.2 \%)$ & $6(5.3 \%)$ & $13(11.5 \%)$ & 11 & $40(74.1 \%)$ & $3(5.6 \%)$ & $11(20.4 \%)$ & 15 & 2.334 & 0.127 \\
\hline 17. I feel angry about the situation. & $86(76.1 \%)$ & $4(3.5 \%)$ & $23(20.4 \%)$ & 5 & $34(63.0 \%)$ & $1(1.9 \%)$ & $19(35.2 \%)$ & 9 & 4.270 & 0.039 \\
\hline 19. My emotional well-being suffers. & $86(76.1 \%)$ & $2(1.8 \%)$ & $25(22.1 \%)$ & 4 & $27(50.0 \%)$ & $2(3.7 \%)$ & $25(46.3 \%)$ & 3 & 10.178 & 0.001 \\
\hline $\begin{array}{l}\text { 29. I can't relax because of worrying } \\
\text { about caring. }\end{array}$ & $82(72.6 \%)$ & $10(8.8 \%)$ & $21(18.6 \%)$ & 6 & $28(51.9 \%)$ & $3(5.6 \%)$ & $23(42.6 \%)$ & 5 & 10.853 & 0.001 \\
\hline 30. I feel guilty about the situation. & $111(98.2 \%)$ & 0 & $2(1.8 \%)$ & 18 & $51(94.4 \%)$ & 0 & $3(5.6 \%)$ & 21 & 1.803 & 0.179 \\
\hline \multicolumn{11}{|l|}{ Physical demands of caring } \\
\hline $\begin{array}{l}\text { 6. The person I care for is immobile/has } \\
\text { problems getting about. }\end{array}$ & $103(91.2 \%)$ & $8(7.1 \%)$ & $2(1.8 \%)$ & 18 & $39(72.2 \%)$ & $7(13.0 \%)$ & $8(14.8 \%)$ & 18 & 11.045 & 0.001 \\
\hline 10. It is physically tiring. & $87(77.0 \%)$ & $7(6.2 \%)$ & $19(16.8 \%)$ & 7 & $29(53.7 \%)$ & $5(9.3 \%)$ & $20(37.0 \%)$ & 8 & 8.348 & 0.004 \\
\hline $\begin{array}{l}\text { 13. The person I care for needs a lot of } \\
\text { help with personal care. }\end{array}$ & $98(86.7 \%)$ & $10(8.8 \%)$ & $5(4.4 \%)$ & 16 & $32(59.3 \%)$ & $9(16.7 \%)$ & $13(24.1 \%)$ & 14 & 14.670 & 0.001 \\
\hline 15. My sleep is affected. & $67(59.3 \%)$ & $5(4.4 \%)$ & $41(36.3 \%)$ & 2 & $30(55.6 \%)$ & $2(3.7 \%)$ & $22(40.7 \%)$ & 6 & 0.309 & 0.578 \\
\hline 23. My physical health has suffered. & $90(79.6 \%)$ & $4(3.5 \%)$ & $19(16.8 \%)$ & 7 & $32(59.3 \%)$ & $1(1.9 \%)$ & $21(38.9 \%)$ & 7 & 9.775 & 0.002 \\
\hline 24. The person I care for is incontinent. & $108(95.6 \%)$ & $1(0.9 \%)$ & $4(3.5 \%)$ & 17 & $45(83.3 \%)$ & $3(5.6 \%)$ & $6(11.1 \%)$ & 19 & 3.721 & 0.054 \\
\hline \multicolumn{11}{|l|}{ Restricted social life } \\
\hline $\begin{array}{l}\text { 3. I can't devote enough time to other } \\
\text { family members. }\end{array}$ & $88(77.9 \%)$ & $9(8.0 \%)$ & $16(14.2 \%)$ & 8 & $37(68.5 \%)$ & $1(1.9 \%)$ & $16(29.6 \%)$ & 11 & 5.646 & 0.017 \\
\hline $\begin{array}{l}\text { 8. It restricts my social life/outside } \\
\text { interests. }\end{array}$ & $91(80.5 \%)$ & $8(7.1 \%)$ & $14(12.4 \%)$ & 10 & $38(70.4 \%)$ & $2(3.7 \%)$ & $14(25.9 \%)$ & 13 & 4.798 & 0.028 \\
\hline $\begin{array}{l}\text { 18. I can't see friends as often as l'd } \\
\text { like. }\end{array}$ & $90(79.6 \%)$ & $8(7.1 \%)$ & $15(13.3 \%)$ & 9 & $38(70.4 \%)$ & $2(3.7 \%)$ & $14(25.9 \%)$ & 13 & 4.076 & 0.044 \\
\hline $\begin{array}{l}\text { 20. I can't have a break or take a } \\
\text { holiday. }\end{array}$ & $83(73.5 \%)$ & $14(12.4 \%)$ & $16(14.2 \%)$ & 8 & $34(63.0 \%)$ & $6(11.1 \%)$ & $14(25.9 \%)$ & 13 & 3.433 & 0.064 \\
\hline \multicolumn{11}{|l|}{ Poor family support } \\
\hline \multirow{2}{*}{$\begin{array}{l}\text { 16. Relatives don't keep in touch as } \\
\text { often as l'd like. } \\
28 \text {. Some family members don't help as } \\
\text { much as they could. }\end{array}$} & $89(78.8 \%)$ & $8(7.1 \%)$ & $16(14.2 \%)$ & 8 & $35(64.8 \%)$ & $4(7.4 \%)$ & $15(27.8 \%)$ & 12 & 4.483 & 0.034 \\
\hline & $89(78.8 \%)$ & $5(4.4 \%)$ & $19(16.8 \%)$ & 7 & $35(64.8 \%)$ & $4(7.4 \%)$ & $15(27.8 \%)$ & 12 & 2.709 & 0.100 \\
\hline \multicolumn{11}{|l|}{ Poor professional support } \\
\hline \multirow{2}{*}{$\begin{array}{l}\text { 7. Professional workers don't seem to } \\
\text { appreciate problems carers face. } \\
27 \text {. I don't get enough from the Health } \\
\text { and Social Services. }\end{array}$} & $93(82.3 \%)$ & $6(5.3 \%)$ & $14(12.4 \%)$ & 10 & $43(79.6 \%)$ & $2(3.7 \%)$ & $9(16.7 \%)$ & 17 & 0.563 & 0.453 \\
\hline & $91(80.5 \%)$ & $3(2.7 \%)$ & $19(16.8 \%)$ & 7 & $44(81.5 \%)$ & 0 & $10(18.5 \%)$ & 16 & 0.074 & 0.786 \\
\hline
\end{tabular}


Caring for relatives with chronic obstructive pulmonary disease: how does the disease severity impact on family carers?

\begin{tabular}{|c|c|c|c|c|c|c|c|c|c|c|}
\hline Financial Consequences & & & & & & & & & & \\
\hline 4. It causes financial difficulties. & $76(67.3 \%)$ & $11(9.7 \%)$ & $26(23.0 \%)$ & 3 & $29(53.7 \%)$ & $5(9.3 \%)$ & $20(37.0 \%)$ & 8 & 3.603 & 0.058 \\
\hline 21. My standard of living has fallen. & $83(73.5 \%)$ & $4(3.5 \%)$ & $26(23.0 \%)$ & 3 & $28(51.9 \%)$ & $2(3.7 \%)$ & $24(44.4 \%)$ & 4 & 8.004 & 0.005 \\
\hline
\end{tabular}

Notes: degrees of freedom $(\mathrm{df})=1$.

Chi-square tests were used to compare items rated as "not stressful" and "stressful".

Ranking positions were based on the frequency of the "stressful" column. 


\section{Caring for relatives with chronic obstructive pulmonary disease: how does the disease severity impact on family carers?}

Table 3 - Correlations between Carers' Assessment of Difficulties Index (CADI) - global and subscales - and COPD severity, caregiving hours, self-rated health, anxiety and depression scores.

\begin{tabular}{|c|c|c|c|c|c|c|}
\hline CADI subscales & COPD severity & $\begin{array}{l}\text { Caregiving } \\
\text { hours per week }\end{array}$ & Anxiety & Depression & $\begin{array}{l}\text { Self-rated } \\
\text { physical health }\end{array}$ & $\begin{array}{l}\text { Self-rated } \\
\text { mental health }\end{array}$ \\
\hline Carer-dependent relationship & $0.281^{*}$ & $0.253^{*}$ & $0.301^{*}$ & $0.249^{\star}$ & $0.168^{*}$ & $0.268^{*}$ \\
\hline Reactions to caregiving & $0.236^{*}$ & $0.325^{*}$ & $0.306^{*}$ & $0.320^{*}$ & $0.206^{*}$ & $0.320^{*}$ \\
\hline Physical demands of caring & $0.250^{*}$ & $0.379^{*}$ & $0.367^{*}$ & $0.328^{*}$ & $0.370^{*}$ & $0.388^{*}$ \\
\hline Restricted social life & 0.146 & $0.311^{*}$ & $0.264^{*}$ & $0.158^{*}$ & 0.134 & $0.221^{*}$ \\
\hline Poor family support & 0.139 & $0.197^{*}$ & $0.234^{*}$ & $0.243^{*}$ & 0.126 & $0.174^{*}$ \\
\hline Poor professional support & 0.047 & 0.124 & $0.218^{*}$ & $0.322^{*}$ & 0.065 & 0.093 \\
\hline Financial Consequences & $0.204^{*}$ & $0.334^{*}$ & $0.387^{*}$ & $0.328^{*}$ & $0.365^{\star}$ & $0.399^{*}$ \\
\hline Global Score & $0.308^{*}$ & $0.393^{*}$ & $0.415^{*}$ & $0.361^{*}$ & $0.293^{*}$ & $0.344^{*}$ \\
\hline
\end{tabular}

